\title{
Língua de Gato: usando a linguagem de forma divertida
}

\author{
Alline Kobayashi ${ }^{1}$, Fernanda Freire ${ }^{2}$, Vitor Rocha ${ }^{3}$, André Scherma ${ }^{4}$ \\ ${ }^{1}$ Pós-graduação em Linguística - Instituto de Estudos da Linguagem - Universidade \\ Estadual de Campinas - Campinas - SP - Brasil \\ ${ }^{2}$ Núcleo de Informática Aplicada à Educação - Universidade Estadual de Campinas - \\ Campinas - SP - Brasil \\ ${ }^{3}$ Graduação em Midialogia - Instituto de Artes - Universidade Estadual de Campinas \\ - Campinas - SP - Brasil \\ ${ }^{4}$ Graduação em Ciência da Computação - Instituto de Computação - Universidade \\ Estadual de Campinas - Campinas - SP - Brasil \\ \{allinekobayashi, fmpfreire, mrocha.vitor, andreschermas\}@gmail.br
}

Resumo. Este artigo apresenta o aplicativo Língua de Gato, desenvolvido para iPad, que tem por objetivo a criação de jogos educacionais envolvendo a fala, a leitura e a escrita. O aplicativo, inspirado no tradicional jogo de Palavras Cruzadas, permite a criação de Cruzadas a partir de imagens ou áudios, em substituição às descrições escritas. A depender do propósito do jogo, o jogador pode descobrir a palavra-alvo e explorar a sua escrita ou propor desafios para outro jogador. Tendo como referencial teórico a Neurolinguística Discursiva, o maior diferencial do aplicativo é a flexibilidade, visto que suporta palavras variadas e explora a relação entre imagem, fala, leitura e escrita de maneira divertida e relacionada aos interesses de seus usuários.

\section{O começo}

O aplicativo aqui descrito surgiu a partir de um atividade feita por Alline Kobayashi, André Scherma e Vitor Rocha durante o curso de desenvolvimento para iOS, Brazilian Education Program for iOS Development (BEPiD-Campinas). Em meados de junho, motivados pelo interesse comum na relação tecnologia e educação, Alline, André e Vitor uniram-se para desenvolver algo que envolvesse a leitura e a escrita, tendo como base teórica a Neurolinguística Discursiva, área do mestrado da Alline Kobayashi, sob co-orientação de Fernanda Freire.

A Neurolinguística Discursiva (ND) iniciou-se na década de 80 no Instituto de Estudos da Linguagem da Universidade Estadual de Campinas (IEL/UNICAMP) a partir da tese Diário de Narciso: discurso e afasia (1986) da Prof $^{\mathrm{a}}$ Dr $^{\mathrm{a}}$ Maria Irma Hadler Coudry, orientadora de Alline Kobayashi, e, desde então, vem sendo continuamente reformulada e expandida por meio das várias edições do Projeto Integrado em Neurolinguística discursiva: afasia e infância (CNPq 312522/2013-4). A ND tem como objeto de estudo o funcionamento da linguagem (incluindo a leitura e a escrita) e sua relação com outras atividades cognitivas em meio à vida em sociedade. Sua teorização resulta da articulação de conceitos de autores que veem a linguagem, o cérebro e o sujeito como construções socioculturais, e assume um posto de observação 


\section{CBIE-LACLO 2015}

Anais dos Workshops do IV Congresso Brasileiro de Informática na Educação (CBIE 2015)

predominantemente linguístico (COUDRY e FREIRE, 2010). A qualificação discursiva expressa o modo como a linguagem se apresenta: heterogênea, polissêmica, indeterminada por um lado (FRANCHI, 1977/1992), e determinada ideológica e historicamente, por outro (BAKHTIN, 1929/1999). Essa condição só pode ser percebida quando a linguagem é posta em funcionamento por meio de práticas sociais de uso, daí a centralidade do conceito de interlocução nos estudos neurolinguísticos (COUDRY e FREIRE, 2010). Para sustentar a natureza complexa do funcionamento das línguas naturais, a ND assume um modelo de cérebro também complexo, tal como é proposto por Vygotsky (1934/1984), Luria (1981) e Freud em seus estudos neurofisiológicos (1891/1973).

\section{Cenário de Uso}

O Língua de Gato tem como princípio norteador auxiliar, de forma lúdica, o processo de aquisição e uso da leitura e da escrita, explorando as relações entre a fala (em geral, já conhecida pelo usuário) e a leitura e a escrita, isto é, o sistema alfabético. Com o propósito de constituir uma plataforma composta po diferentes atividades relacionadas à linguagem (fala, leitura e escrita), customizável de acordo com o usuário, escolhemos o jogo de Palavras Cruzadas como a primeira atividade disponível pelo fato de ser amplamente conhecido em nossa cultura, com regras simples e bem estabelecidas, o que facilita a interação usuário/aplicativo. Modificamos o jogo tradicional pensando em usuários em fase de alfabetização e/ou que apresentem algum tipo de dificuldade de linguagem (crianças com dificuldades escolares, adultos com lesão cerebral que apresentam dificuldades para ler e escrever, etc.).

No jogo tradicional aparecem sequências de quadradinhos que se cruzam e no início de cada uma das sequências aparece algum tipo de enunciado a partir do qual o jogador infere, auxiliado pelo número de quadradinhos disponíveis que corresponde ao número de letras da palavra-alvo, qual palavra deve ser escrita (por exemplo: se o enunciado é "Capital da Itália" e são exibidos quatro quadradinhos em sequência, o jogador deve escrever ROMA). No Língua de Gato, as palavras a serem descobertas e, consequentemente, escritas, se vinculam ou a uma representação visual ou a uma representação sonora que podem ser modificadas a cada jogada. Dessa forma, ao se criar um jogo, o usuário deve inserir as palavras-alvos (a serem escritas) por meio de imagens que as ilustrem (através da câmera ou da galeria de fotos do tablet) ou por meio da gravação de áudios.

Considerando essas caracterísitcas, o Língua de Gato tem como público alvo crianças em fase de aquisição ou uso da leitura e da escrita (jogadores) e mediadores que poderão auxiliar e intervir nesse processo (criadores). Cabe ao mediador - pais, professores, fonoaudiólogos, pedagogos, entre outros - inserir as entradas do jogo de acordo com o sujeito a quem se destina, incluindo o áudio ou a imagem de palavras que fazem parte do universo daquela criança/adulto e/ou são de interesse do ponto de vista educacional ou clínico. Os jogadores, por sua vez, podem ser crianças e jovens que estão em fase de aquisição e ou uso de leitura e escrita (a partir dos 6 anos) ou adultos que apresentam dificuldades de linguagem. Pode-se, ainda, explorar a utilização do aplicativo aos pares, isto é, crianças podem criar jogos para outras crianças ou adultos com dificuldades de linguagem podem criar jogos para outros adultos. 


\section{CBIE-LACLO 2015}

Anais dos Workshops do IV Congresso Brasileiro de Informática na Educação (CBIE 2015)

A maior parte dos aplicativos disponíveis na App Store relacionada a essa temática segue uma orientação cartilhesca: apresenta as letras do alfabeto associadas a imagens de palavras cuja letra inicial corresponde ao seu som inicial (B de bola, L de lua, $\mathrm{M}$ de macaco) ou, mesmo, ao nome da própria letra (letra cê de cebola, letra dê de dedo). Esse princípio, denominado de acrofônico, não é generalizável, uma vez que se aplica a apenas um subconjunto de palavras da lingua, deixando de fora outros conhecimentos importantes relacionados à escrita, como a categorização gráfica e a categorização funcional das letras, orientados pela ortografia,da língua (MassiniCagliari e Cagliari, 1999/2008). Além disso, esses aplicativos são bastante infantilizados e, portanto, desinteressantes para outras faixas etárias.

A observação e análise do uso de alguns desses aplicativos por crianças e jovens com dificuldades de linguagem nos levaram a repensar suas características à luz da teorização da ND que prevê uma relação de concomitância entre as imagens acústica, motora e visual da palavra falada, lida e escrita e que pressupõe a relação com o outro, ocasião em que a linguagem ganha sentido (Freud, 1891/1973; Coudry 2010). Assim, pensamos em um aplicativo que coloca em relação as imagens acústica, motora e visual das palavras e, em especial, de palavras que façam sentido aos seus usuários, isto é, ou que façam parte do seu universo de interesses ou que possam ser inseridas em seu universo de uma maneira social e culturalmente contextualizada. A entrada por meio de imagens faz com que o usuário associe aquela determinada imagem a uma palavra, supostamente, já conhecida pela fala, o que o leva a recordar da sua imagem acústica que deverá, então, ser associada a sua imagem gráfica (imagem visual das letras); de forma similar, a entrada por meio do áudio faz com que o usuário associe aquela imagem acústica a sua imagem gráfica, refletindo sobre as diferenças que podem haver entre a palavra falada e a palavra escrita, um desafio para os iniciantes no mundo das letras. Foi, então, pensando nessas orientações, que optamos por um jogo customizável, isto é, ajustável às necessidades linguístico-cognitivas de diferentes usuários.

Assim, dois são os nossos desafios ao desenvolver o Língua de Gato: (i) divertir sem infantilizar e (ii) permitir a exploração da escrita a partir das relações entre fala, leitura e escrita.

\section{Desenvolvimento}

O desenvolvimento do aplicativo teve início na segunda quinzena de junho e ocorre durante o horário em que Alline, Vitor e André frequentam o BEPiD. Como desenvolvemos este aplicativo paralelamente ao curso de iOS e às nossas atividades acadêmicas (graduação ou mestrado), estamos em uma fase inicial do aplicativo. Com o objetivo de aprender uma linguagem de programação recém criada, resolvemos desenvolver o aplicativo em Swift, linguagem própria para desenvolvimento de aplicativos/softwares da Apple (iPhone, iPad, OS X) lançada em 2014.

Nossa primeira reunião ocorreu no dia 10 de junho e nela definimos as funcionalidades principais do aplicativo derivadas das duas ações centrais: criar jogo e jogar. Listadas as tarefas a serem executadas, foram atribuídas a elas prioridade: P1 tarefas de alta prioridade, que vêm sendo feitas desde meados de junho até o fechamento deste artigo; P2 - tarefas a serem executadas a curto prazo (durante julho e agosto) e entregável no dia 1 de setembro para a versão apresentável do aplicativo; P3 - 
Anais dos Workshops do IV Congresso Brasileiro de Informática na Educação (CBIE 2015)

tarefas a serem executadas a partir de setembro. A Tabela 1 abaixo lista nosso planejamento de desenvolvimento.

Tabela 1. Lista de atividades a serem desenvolvidas

\begin{tabular}{|c|c|c|c|c|}
\hline \multirow{2}{*}{ Categoria } & \multirow{2}{*}{ Tarefa/Funcionalidade } & \multicolumn{3}{|c|}{ Prioridade } \\
\hline & & P1 & $\mathbf{P 2}$ & P3 \\
\hline \multirow{6}{*}{$\begin{array}{l}\text { Tela criação da } \\
\text { palavra cruzada }\end{array}$} & $\begin{array}{l}\text { Inserir imagem da câmera ou } \\
\text { galeria de fotos }\end{array}$ & $\mathbf{X}$ & & \\
\hline & Inserir áudio & & $\mathbf{X}$ & \\
\hline & Mostrar imagem inserida & $\mathbf{X}$ & & \\
\hline & Mostrar áudio inserido & & $\mathbf{X}$ & \\
\hline & $\begin{array}{l}\text { Editar palavras inseridas } \\
\text { (excluir) }\end{array}$ & & $\mathbf{X}$ & \\
\hline & $\begin{array}{l}\text { Possibilitar a edição da } \\
\text { imagem a ser inserida } \\
\text { (recortar como um quadrado) }\end{array}$ & & $\mathbf{X}$ & \\
\hline \multirow{5}{*}{ Tela do jogo } & $\begin{array}{l}\text { Pesquisar sobre SpriteKit e } \\
\text { como exibir a cruzadinha na } \\
\text { tela (matriz) }\end{array}$ & $\mathbf{X}$ & & \\
\hline & $\begin{array}{l}\text { Exibir uma lista de palavras na } \\
\text { cruzadinha, uma embaixo da } \\
\text { outra (exibição simples, sem } \\
\text { que as palavras se cruzem). }\end{array}$ & & $\mathbf{X}$ & \\
\hline & $\begin{array}{l}\text { Versão jogável com a exibição } \\
\text { simples das palavras. }\end{array}$ & & $\mathbf{X}$ & \\
\hline & $\begin{array}{l}\text { Ao inserir uma letra "errada", } \\
\text { gerar algum feedback visual } \\
\text { negativo para o jodagor. }\end{array}$ & & $\mathbf{X}$ & \\
\hline & $\begin{array}{l}\text { Permitir } 2 \text { modalidades de } \\
\text { jogo: uma na qual as letras } \\
\text { arrastáveis são apenas as } \\
\text { possíveis letras que se } \\
\text { encaixam nas palavras ou } \\
\text { outra na qual tem-se todas as }\end{array}$ & & $\mathbf{X}$ & \\
\hline
\end{tabular}




\begin{tabular}{|c|c|c|c|c|}
\hline & $\begin{array}{l}\text { letras do alfabeto sempre } \\
\text { disponíveis. }\end{array}$ & & & \\
\hline & $\begin{array}{l}\text { Feedback positivo ao terminar } \\
\text { uma palavra corretamente. }\end{array}$ & & $\mathbf{X}$ & \\
\hline & $\begin{array}{l}\text { Feedback de áudio (leitura da } \\
\text { palavra) ao terminar de } \\
\text { preencher uma palavra. }\end{array}$ & & & $\mathbf{X}$ \\
\hline & Logo/ícone & $\mathbf{X}$ & & \\
\hline Identidade visual & Cores & $\mathbf{X}$ & & \\
\hline & Testar com crianças e adultos & & $\mathbf{X}$ & \\
\hline & $\begin{array}{l}\text { Criar um algoritmo para } \\
\text { cruzar as palavras }\end{array}$ & & & $\mathbf{X}$ \\
\hline & $\begin{array}{l}\text { Banco de Dados: armazenar os } \\
\text { jogos criados }\end{array}$ & & & $\mathbf{X}$ \\
\hline Outros & Definir a licença do aplicativo & & & $\mathbf{X}$ \\
\hline
\end{tabular}

\section{Apresentação do software}

A primeira versão do aplicativo, estimada para setembro, possibilitará ao usuário informar 6 palavras e suas respectivas imagens ou áudios para a criação da cruzada (tela de criação da Palavra Cruzada, Figura 1) e, a partir de tais palavras, será gerada uma tela de jogo simples na qual as palavras não estão cruzadas, mas exibidas uma embaixo da outra conforme a Figura 2. 


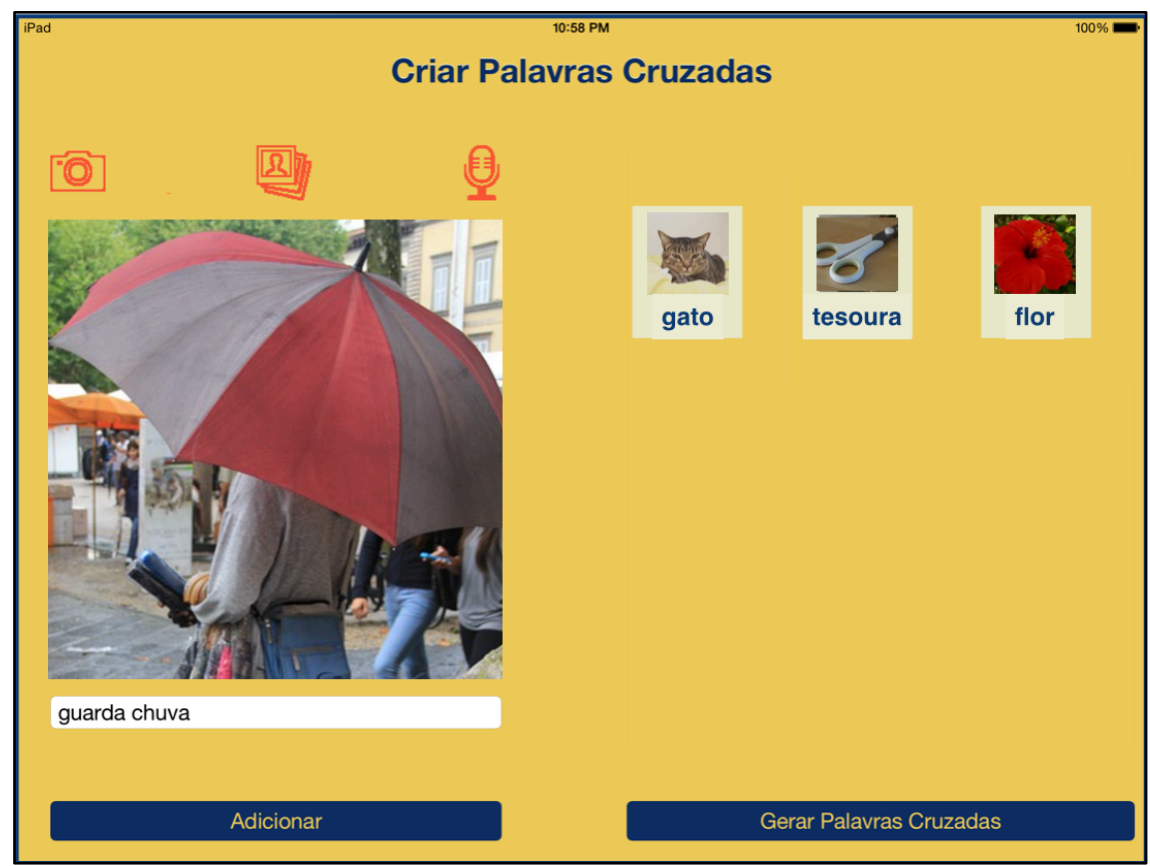

Figura 1. Tela para criação da Palavra Cruzada

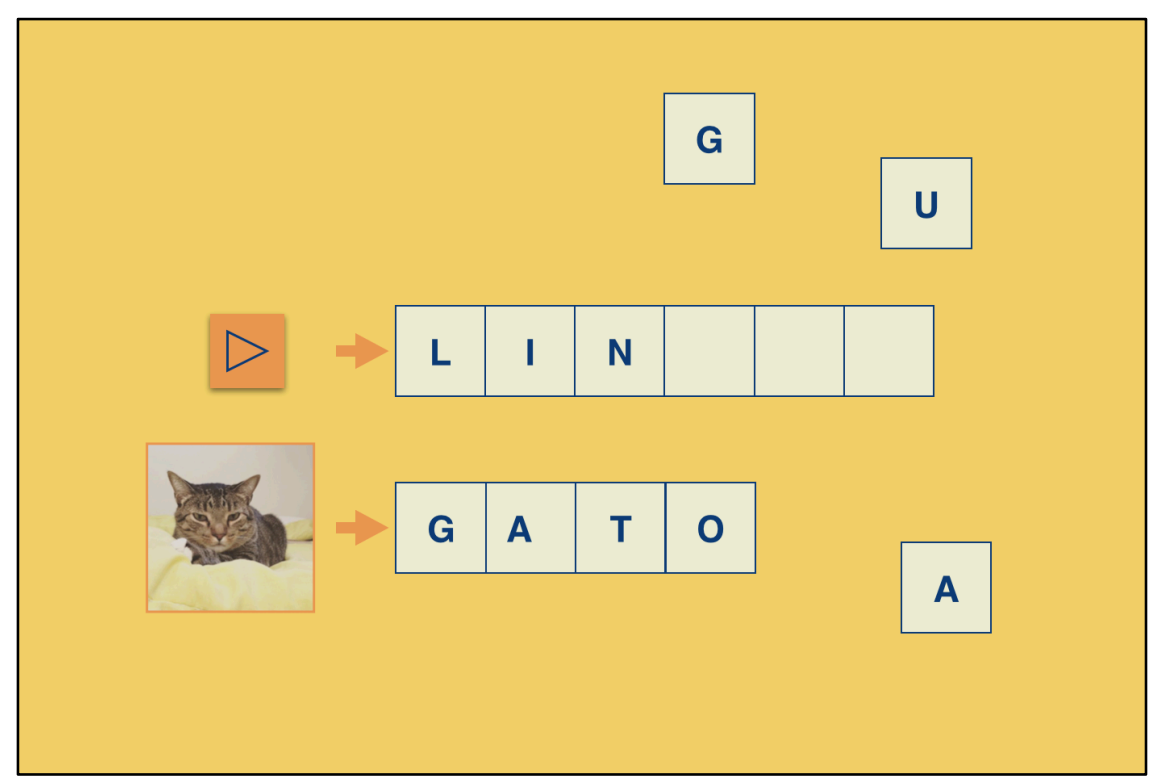

Figura 2: Tela de jogo simples da Palavra Cruzada ( $1^{\text {a }}$ versão)

$\mathrm{Na}$ versão final do aplicativo, por sua vez, as palavras serão apresentadas cruzadas e será incluído a função de ouvir a palavra escrita caso ela esteja escrita de forma não convencional. 


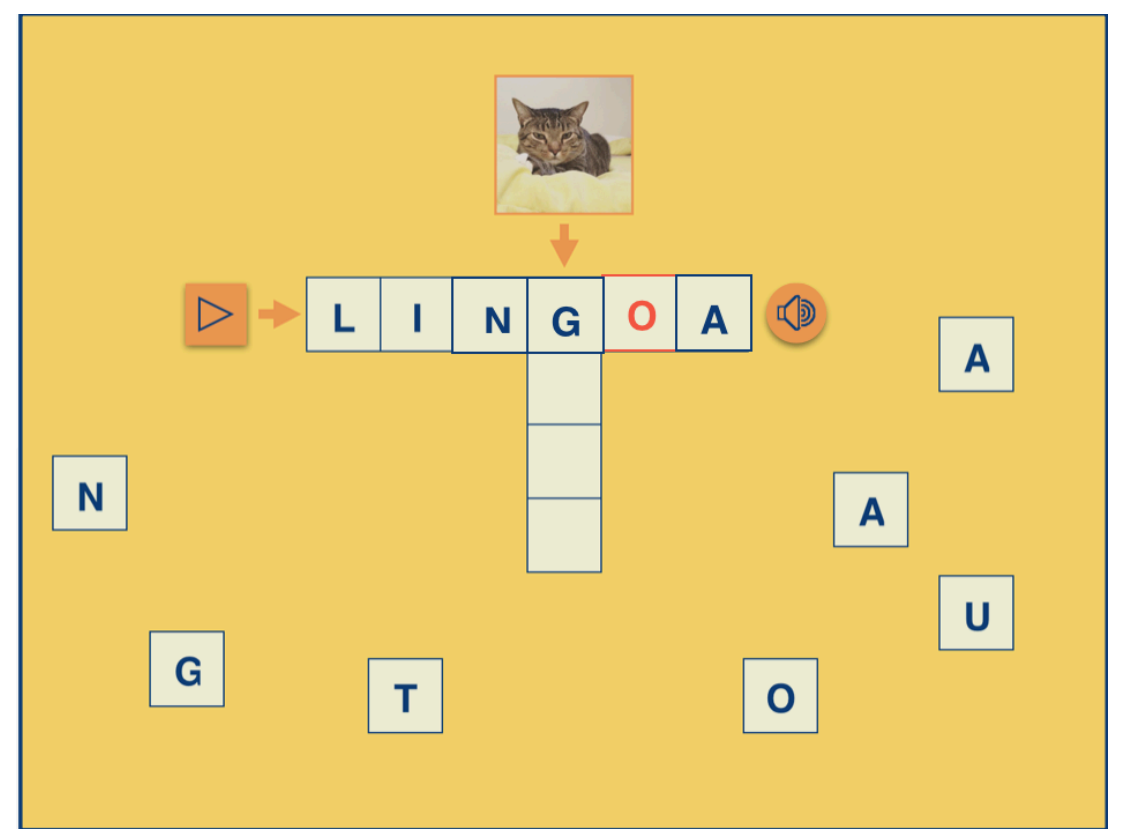

Figura 3: Tela de jogo completa (versão final)

A tela apresentada na Figura 1 encontra-se em produção, já sendo possível inserir imagens da câmera do iPad e da biblioteca de fotos. A próxima funcionalidade a ser implementada desta tela é a gravação do áudio. A tela de jogo ainda não está funcional.

\section{Considerações finais}

O aplicativo Língua de Gato: usando a linguagem de forma divertida surge a partir necessidade de se ter um aplicativo interessante que trabalhe a fala, a leitura e escrita a partir das necessidades particulares do sujeito e com elementos que fazem parte do seu universo. Ao pensar algo para além do "bê-a-bá", desejamos construir um aplicativo com potencial de trabalhar a linguagem em toda a sua complexidade e abranger diferentes públicos alvo, como os jovens e adultos. Embora ainda encontre-se em fase embrionária, vemos nesse aplicativo um potencial inovador e a porta de entrada para o desenvolvimento de outros jogos que envolvam a linguagem. Pode-se dizer que o Língua de Gato é o fruto recente da união entre a computação e a Neurolinguística Discursiva.

\section{Referencias}

Vygotsky, Lev Semionovith. [1934] 1987. Pensamento e linguagem. Trad. Jeferson Luiz Camargo. São Paulo: Martins Fontes.

Vygotsky, Lev Semionovith. 1984. A formação social da mente. São Paulo: Martins Fontes.

Luria, Alexander Romanovich (1981) Fundamentos de Neuropsicologia. São Paulo: Cultrix 
Anais dos Workshops do IV Congresso Brasileiro de Informática na Educação (CBIE 2015)

Freud, Sigmund. [1891] 1973. La afasia. Tradução de Ramón Alcalde. Buenos Aires, Ediciones Nueva Visión

Coudry, Maria Irma Hadler; Freire, Fernanda Maria Pereira. 2010. Pressupostos teóricoclínicos da Neurolinguística Discursiva (ND), em Coudry, M. I. H.; Freire, F. M. P.; Andrade, M. L. F.; Silva, M. A.(orgs), Caminhos da Neurolinguística Discursiva: teorização e práticas com a linguagem. Campinas, SP: Mercado de Letras:

Coudry, Maria Irma Hadler. 2010b. Diálogo com a Neurolinguística: para a formação de professores, em Serrani, S. (org.), Letramento, discurso e trabalho docente. Vinhedo, SP: Editora Horizonte: 88-99.

Bakhtin, Mikhail. [1929] 1999. Marxismo e Filosofia da Linguagem. São Paulo, Hucitec.

Franchi, C. (1977/92) Linguagem - Atividade Constitutiva. In: Cadernos de Estudos Linguísticos 22. Campinas: IEL/UNICAMP. (p.9-39).

MASSINI-CAGLIARI, G.; CAGLIARI, L. C. (1999/2008) (orgs.) Diante das letras: a escrita na alfabetização. Campinas, SP: Mercado de Letras. (p. 97-110). 